\title{
Установка по измерению термоэлектрических свойств ультратонких проволок
}

\author{
(C) О.Н. Урюпин, А.А. Шабалдин \\ Физико-технический институт им. А.Ф. Иофрфе Российской академии наук, \\ 194021 Санкт-Петербург, Россия \\ E-mail: O.uryupin@mail.ioffe.ru
}

(Поступила в Редакцию 20 декабря 2018 г. В окончательной редакции 24 декабря 2018 г. Принята к публикации 28 декабря 2018 г.)

Создана экспериментальная установка для измерения термоэлектрических свойств полупроводниковых нанопроволок диаметром до 5 нм в диэлектрических матрицах. Установка позволяет измерять электросопротивление и термоэдс наноструктурированных образцов в диапазоне температур 77-400 K.

DOI: 10.21883/FTP.2019.05.47567.25

\section{1. Введение}

В настоящее время ведутся активные поиски материалов и структур с безразмерной термоэлектрической эффективностью $Z T \gg 1$. При этом существенное увеличение термоэлектрической эффективности по сравнению со значением $Z T=1$ было экспериментально получено только в наноструктурах [1-3].

Одним из вариантов получения наноструктурных термоэлектриков является заполнение наноразмерных диэлектрических материалов, таких как хризотил-асбест и пористые стекла, полупроводниковым материалом с высокими значениями термоэдс. Природный материал хризотил-асбест (гидросиликат магния) состоит из тончайших трубочек-фибрилл с характерным внутренним диаметром 5-7 нм [4]. Поры трубочек изолированы друг от друга и при заполнении полупроводником создают пучки параллельных независимых нанопроволок длиной до 10 мм. Каркас пористых стекол состоит в основном из $\mathrm{SiO}_{2}[5,6]$. Поры в таком стекле образуют трехмерную сеть, состоящую из коротких каналов. Характерной особенностью пористых стекол является узкий максимум в распределении пор по их поперечным размерам. Ширина этого максимума на половине высоты равна $\sim 0.15$ от среднего диаметра пор в образце [7]. Изменяя условия синтеза стекол, можно достичь размера среднего диаметра пор в несколько мкм. Термоэлектрические структуры, полученные в таких изолирующих матрицах, требуют создания специальных установок по измерению их термоэлектрических свойств.

\section{2. Образцы}

Образцы создавались заполнением каналов диэлектрических матриц расплавом полупроводникового материала под действием высокого гидростатического давления. Ранее на аналогичных образцах измерялись в основном электрические свойства. Важным моментом для исследования электрических и термоэлектрических свойств таких образцов является создание надежных омических контактов. Разные авторы искали различные пути создания надежных электрических контактов.

В работе [8] электропроводность пучков полупроводниковых нанопроволок в асбестовой матрице вдоль образцов измерялась с использованием ртутных контактов, находящихся под давлением. В работе [9] в большинстве случаев контакты к аналогичным пучкам нанопроводов создавались вакуумным осаждением индия, в некоторых случаях для этой цели использовалась эвтектика $\mathrm{In}-\mathrm{Ga}$. Для измерения электропроводности использовался двухконтактный метод. Авторами не была найдена разница между данными проводимости для образцов с обоими типами контактов, но осажденные в вакууме контакты были гораздо более стабильными. В работе [10] при измерении фотоэдс наноструктур $\mathrm{GaN}$ в асбестовой матрице электроды $(1 \times 1$ мм $)$ наносились на образцы серебряной пастой, межэлектродный интервал составлял 1 мм. В работе [11] при измерении электрических свойств одиночных одномерных проводов висмута электрические контакты были сделаны из латунных проводов, прикрепленных серебряной эпоксидной смолой к золотым подушечкам, осажденным в вакуумном испарителе. В работе [12] как двухзондовые, так и четырехзондовые контакты к одиночным нанопроволкам $\mathrm{NbSe}_{3}$ изготавливались из золота с помощью электронно-лучевой литографии. В работе [13] контакты к тонким образцам $\mathrm{TaS}_{3}$ и $\mathrm{NbSe}_{3}$ были получены как холодной пайкой индием, так и вакуумным напылением индия. Измерения проводились двухконтактным методом.

Проведя ряд экспериментов, мы разработали свой метод получения надежных электрических контактов пучков нанопроволок, используя холодную пайку индием с сохранением таких контактов под давлением на время проведения эксперимента. Для этого в измерительной установке каждый индиевый контакт вставлялся в отдельные зажимы из меди. Давление на контакты подбиралось к каждому образцу до достижения стабилизации электросопротивления на минимальном уровне. 
Это означало, что электрический контакт создан для наибольшего количества полупроводниковых нанопроволок в исследуемом образце.

Изготовленные из пучков нанопроволок образцы имели длину $1-2 \mathrm{мм} \mathrm{и} \mathrm{сечение} \sim 0.01 \mathrm{~mm}^{2}$, а расстояние между индиевыми электродами устанавливалось $\sim(0.3-0.1)$ мм. При этом образцы наноструктур могли иметь высокие электрические сопротивление, $\sim\left(10^{6}-10^{8}\right)$ Ом, так как в процессе изготовления не все каналы в исходных матрицах заполняются полупроводниковым материалом. Такое сопротивление накладывает дополнительные ограничения по использованию термопар при измерении перепада температуры на образце.

\section{3. Измерение температурной зависимости термоэдс}

Разработанная нами экспериментальная установка предназначена для измерения термоэдс и кондактанса пучков нанопроволок в интервале температур 80-400 K. Для измерения термоэдс в установке использован сравнительный метод, при котором перепад температуры $\Delta T$ на образце рассчитывают исходя из известной термоэдс эталонного образца. Такой подход не требует прямого измерения $\Delta T$ и повышает точность результата благодаря увеличению отношения сигнал/шум.

Для измерения термоэдс использовались высокоомные вольтметры с входным сопротивлением не менее 10 ГОм. Основные элементы экспериментальной установки представлены на рис. 1.

Измерительный блок был помещен в вакуумную камеру. Основным элементом измерительного блока является держатель с располагающимися на нем двумя парами зажимов, в одной из которых зажаты индиевые электроды исследуемого образца, а в другой - эталон. В качестве эталона использовался калиброванный

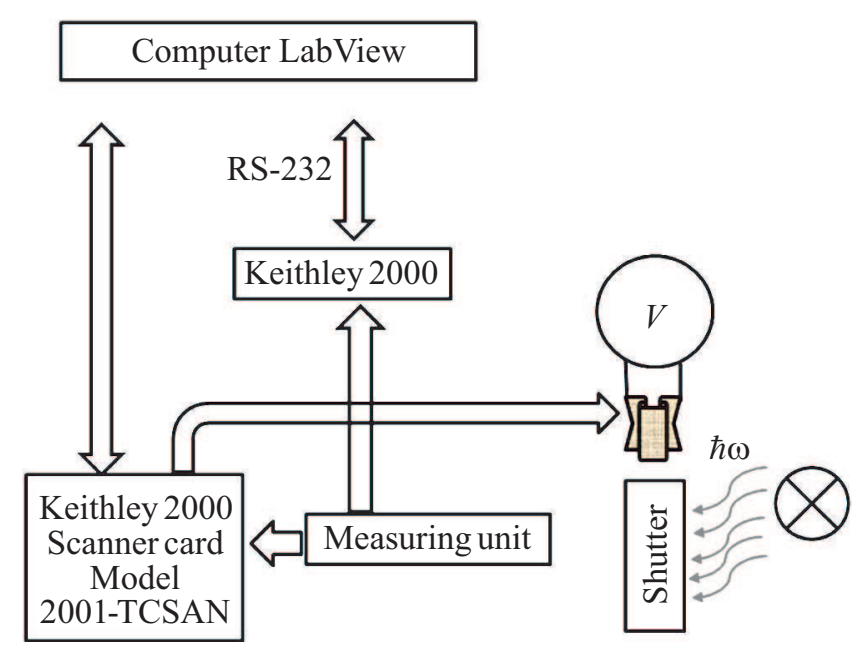

Рис. 1. Схема управления установкой для измерения температурных зависимостей термоэдс.
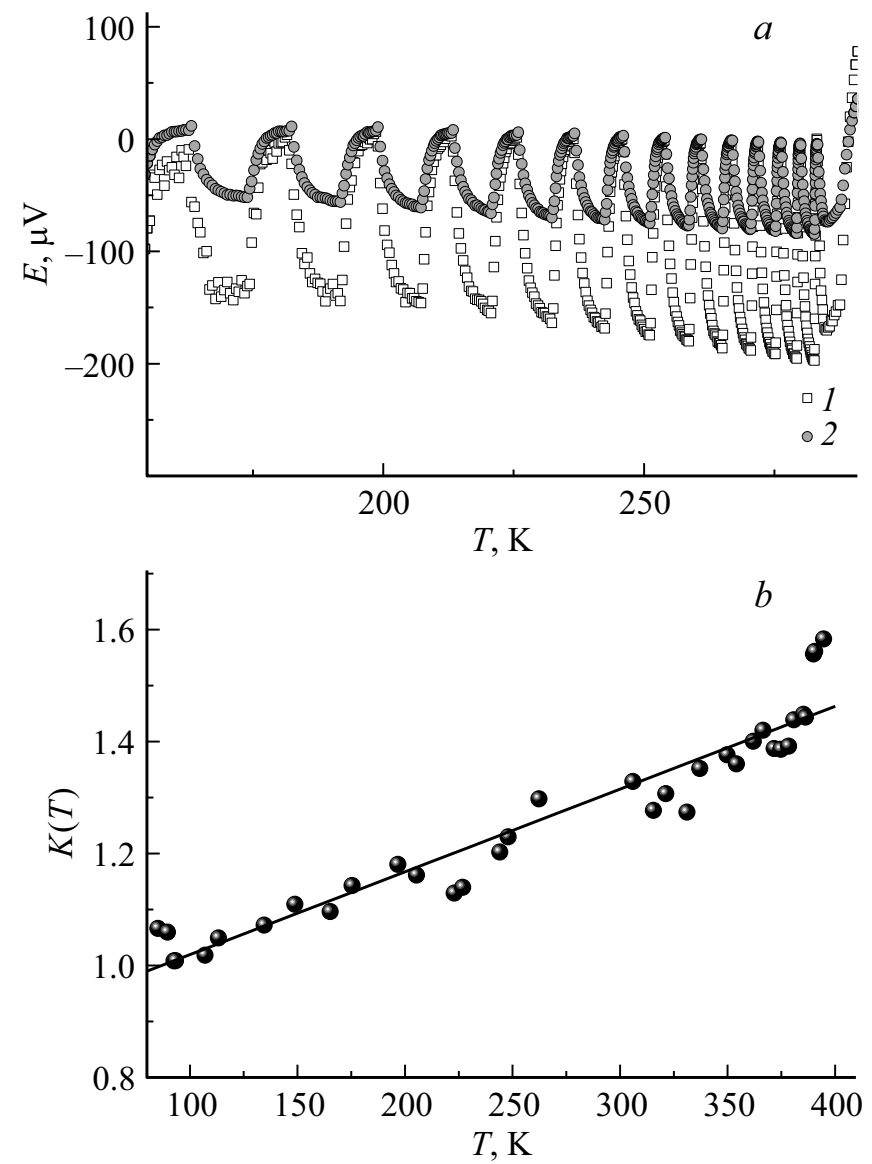

Рис. 2. Пример записи экспериментальных данных при измерении температурных зависимостей термоэд $E(a)$ и температурная зависимость поправочного коэффициента для расчета термоэдс образцов $(b) .1-$ сигнал от образца; $2-$ сигнал от эталона.

константан. Для уменьшения электрических наводок в измерительных цепях зажимы были электрически изолированы от корпуса с сохранением необходимого теплового контакта. Для исключения электрических наводок и электрического шунтирования образца за счет токов утечек цепей перепад температуры на образцах создавался освещением зачерненной приемной пластины горячих зажимов. С целью минимизации паразитных тепловых потоков обе пары зажимов закрывались тепловым экраном.

Измерение температурной зависимости термоэдс исследуемого объекта проводилось одновременно с измерением термоэдс эталона (рис. 2). В начале эксперимента в измерительный блок заливался жидкий азот и образец охлаждался. Затем световой пучок нагревал горячие зажимы до насыщения сигнала на вольтметре, после этого опускался защитный экран и температуры зажимов выравнивались. В последующем измерительные циклы повторялись, а температура образца плавно росла. Результаты измерения поступали в компьютер, проводилась интерполяция результатов измерения, и 


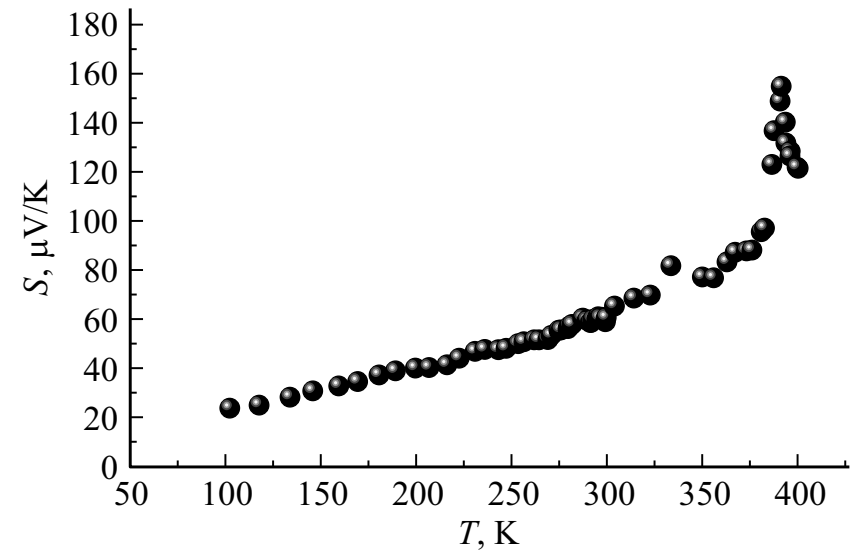

Рис. 3. Температурная зависимость коэффициента термоэдс $S$ пучка нанопроволок $\operatorname{InSb}\langle\mathrm{Zn}\rangle$ в каналах асбеста.

рассчитывался коэффициент термоэдс образца для конкретных температурных значений по формуле

$$
S_{s}=S_{\mathrm{et}} U_{s} K(T) / U_{\mathrm{et}},
$$

где $S_{\text {et }}-$ коэффициент термоэдс эталона, $U_{s}-$ напряжение на образце, $U_{\text {et }}-$ напряжение на эталоне, $K(T)$ - поправочный коэффициент, учитывающий небольшое различие перепадов температуры на образце и эталоне, предварительно измеренный при одновременном измерении двух эталонов.

Тестирование установки проводилось при измерении термоэдс монокристалла $\mathrm{Bi}_{0.85} \mathrm{Sb}_{0.15}$. Выбор образца обусловлен высокой однородностью, стабильностью свойств, высокими значениями термоэдс и практической изотропностью термоэлектрических свойств. Различие коэффициента термоэдс одного и того же кристалла $\mathrm{Bi}_{0.85} \mathrm{Sb}_{0.15}$, измеренного абсолютным и относительным методами, в интервале температур 80-300 К не превысило $10 \%$.

Пример температурной зависимости коэффициента термоэдс для пучка нанопроволок $\operatorname{InSb}\langle\mathrm{Zn}\rangle$ в каналах асбеста с внутренним диаметром 5-7нм, измеренной на данной установке, приведен на рис. 3. Видно, что термоэдс практически линейно растет с температурой, что хорошо согласуется с теорий латтинжеровской жидкости $[14,15]$.

\section{4. Измерение температурной зависимости кондактанса}

Для квазиодномерных структур невозможно рассчитать удельное сопротивление, поэтому для них введено понятие кондактанса - величины, обратной электрическому сопротивлению. Схема управления экспериментальной установки для измерения температурной зависимости кондактанса приведена на рис. 4. Тот же измерительный блок, описанный выше, так же помещался в вакуумную камеру, но перепад температур на зажимах не создавался. Измерение проводилось двухзондовым методом. При тестировании установки по измерению кондактанса так же использован монокристалл $\mathrm{Bi}_{0.85} \mathrm{Sb}_{0.15}$. Отличие электросопротивления образца, измеренного на нашей установке, от полученных ранее при измерении четырехзондовым методом, во всем температурном интервале $77-300 \mathrm{~K}$ не превысило 7\%. На рис. 5 приведен пример температурной зависимости кондактанса пучка нанопроволок $\operatorname{InSb}\langle\mathrm{Zn}\rangle$ в каналах асбеста с внутренним диаметром 5-7 нм, измеренной на данной установке.

Важной особенностью полученных результатов является одновременный быстрый рост термоэдс и проводимости в образцах нанопроволок $\operatorname{InSb}\langle\mathrm{Zn}\rangle$ в каналах асбеста при температурах $>300 \mathrm{~K}$, что благоприятно для достижения высокого фактора мощности преобразования энергии.

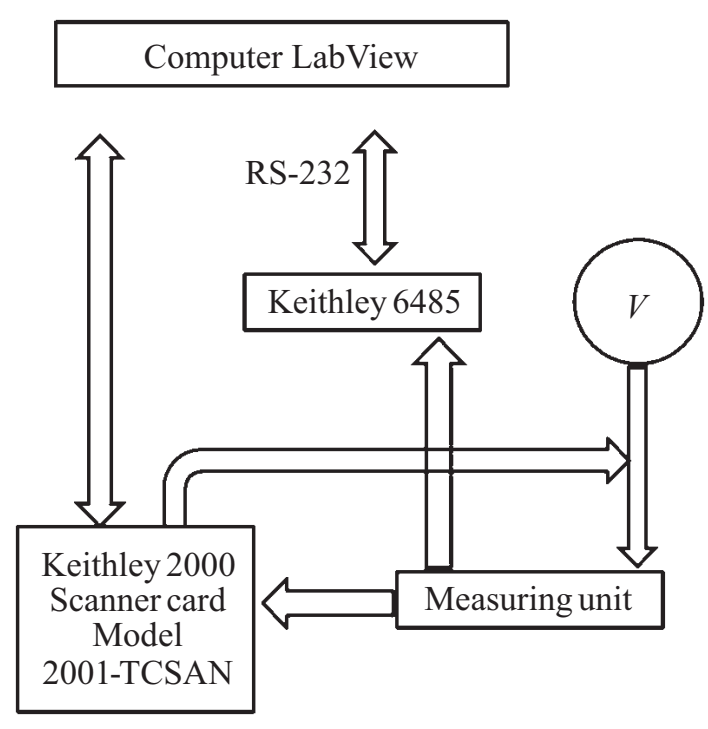

Рис. 4. Схема управления установкой для измерения температурных зависимостей кондактанса.

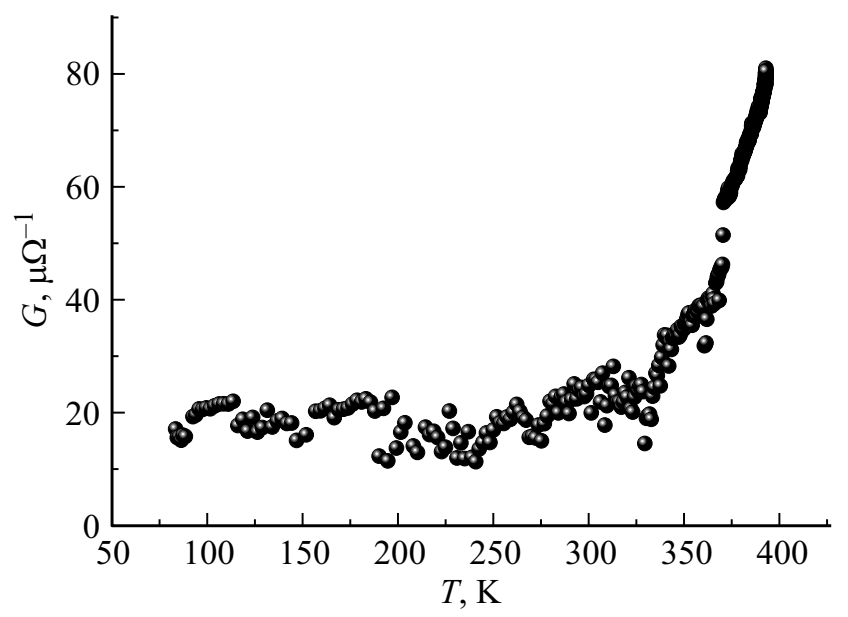

Рис. 5. Температурная зависимость кондактанса $G$ пучка нанопроволок $\operatorname{InSb}\langle\mathrm{Zn}\rangle$ в каналах асбеста. 
Измерение вольт-амперных характеристик осуществлялось при стабилизации температуры 77 и $300 \mathrm{~K}$ путем плавного изменения подаваемого на образцы напряжения.

Данная установка апробирована и для других типов образцов, таких как полупроводниковые материалы в пористых стеклах [16], полупроводниковые микропроволоки в стеклянной оболочке [17], игольчатые полупроводниковые материалы [18], углеродные волокна с разным наполнителем [19].

\section{5. Заключение}

Создана и апробирована экспериментальная установка для измерения температурных зависимостей термоэлектрических свойств ультратонких полупроводниковых материалов с малыми диаметрами, до 5 нм. Данная установка позволяет получать надежные результаты измерений для пучков полупроводниковых нанопроволок даже в изолирующих матрицах в диапазоне температур $77-400 \mathrm{~K}$.

\section{Список литературы}

[1] R. Venkatasubramanian, E. Siivola, T. Colpitts, B. O'Quinn. Nature, 413, 597 (2001).

[2] T.C. Harman, P.J. Taylor, M.P. Walsh, B.E. LaForge. Science, 297, 2229 (2002).

[3] T.C. Harman, M.P. Walsh, B.E. LaForge, G.W. Turner. J. Electron. Mater., 34, L19 (2005).

[4] Y. Kumzerov, S. Vakhrushev. In: Encyclopedia of Nanoscience and Nanotechnology, ed. by H.S. Nalwa (American Scientific Publishers, Los Angeles, 2004) v. 7, p. 811.

[5] D. Enke, F. Janowski, W. Schwieger. Microporous and Mesoporous Mater., 60, 19 (2003).

[6] P. Hofmann. Prog. Surf. Sci., 81, 191 (2006).

[7] P. Levitz, G. Ehret, S.K. Sinha, J.M. Drake. J. Chem. Phys., 95, 6151 (1991).

[8] M.S. Ivanova, Y.A. Kumzerov, V.V. Poborchii, Y.V. Ulashkevich, V.V. Zhuravlev. J. Microporous Mater., 4, 319 ( 1995).

[9] S.V. Zaitsev-Zotov, Yu.A. Kumzerov, Yu.A. Firsov, P. Monceau. J. Phys.: Condens. Matter, 12, L303 (2000).

[10] M. Bryushinin, V. Golubev, Y. Kumzerov, D. Kurdyukov, I. Sokolov. Appl. Phys. B, 95, 489 (2009).

[11] T.E. Huber, M.J. Graf. Phys. Rev. B, 60, 16800 (1999).

[12] E. Slot, M.A. Holst, H.S.J. van der Zant, S.V. Zaitsev-Zotov. Phys. Rev. Lett., 93, 176602 (2004),

[13] S.V. Zaitsev-Zotov, V.Ya. Pokrovskii, P. Monso. JETP Lett., 73 (1), 29 (2001).

[14] C.L Kane, M.P.A. Fisher. Phys. Rev. Lett., 76, 3192 (1996).

[15] I.A. Romanovsky, I.V. Krive, V. Bogachek, U. Landman. Phys. Rev. B, 65, 075115 (2002).

[16] O.N. Uryupin, A.A. Shabaldin. Semiconductors, 51, 733 (2017).

[17] L.D. Ivanova, V.V. Molokanov, A.V. Krutilin, P.P. Umnov, N.V. Umnova, O.N. Uryupin, A.A. Shabaldin. J. Thermoelectricity, 4, 43 (2013).
[18] F.Yu. Solomkin, V.K. Zaitsev, N.F. Kartenko, A.S. Kolosova, A.T. Burkov, O.N. Uryupin, A.A. Shabaldin. Tech. Phys., 55, 750 (2010).

[19] D.K. Ivanov, K.G. Ivanov, O.N. Uryupin. Semiconductors, 51, 834 (2017).

Редактор Л.В. Шаронова

\section{Setup for measuring thermoelectric properties of ultra-thin wires}

\author{
O.N. Uryupin, A.A. Shabaldin \\ loffe Institute, \\ 194021 St. Petersburg, Russia
}

Abstract An experimental setup was created to measure the thermoelectric properties of semiconductor nanowires with a diameter of up to $5 \mathrm{~nm}$ in dielectric matrices. The installation allows to measure the electrical resistance and thermoelectric power of nanostructured samples in the temperature range $77-400 \mathrm{~K}$.

Публикация материалов Конференции завершена. 